\title{
Ю.М. Горлин
}

Институт социального анализа и прогнозирования Российской академии народного хозяйства и государственной службы при Президенте Российской Федерации, Москва

\section{А.А. Салмина}

Институт социального анализа и прогнозирования Российской академии народного хозяйства и государственной службы при Президенте Российской Федерации, Москва

\section{В.Ю. Ляшок}

Институт социального анализа и прогнозирования Российской академии народного хозяйства и государственной службы при Президенте Российской Федерации, Москва

\section{Эмпирические пенсионные индикаторы: межстрановые сравнения и методология для России ${ }^{1}$}

\begin{abstract}
Аннотация. В статье с учетом анализа зарубежных и российских подходов к оценке достаточности уровня пенсионного обеспечения предложена система эмпирических индикаторов для России. Одна группа этих индикаторов, предназначенная для проведения межстрановых сравнений, базируется на методологии Европейской комиссии. Представлены результаты расчетов предложенных индикаторов на данных российской статистики, позволившие сравнить уровень пенсий в России и странах Европейского союза. В статье определены ограничения индикаторов для межстрановых сравнений с точки зрения оценки уровня пенсионных выплат в рамках российской системы обязательного пенсионного страхования. Для более адекватной оценки достаточности этих выплат разработана вторая группа индикаторов, учитывающих особенности системы пенсионного обеспечения в России. Отличительная особенность предлагаемого подхода к оценке эмпирических индикаторов в том, что она ориентирована прежде всего на оценку достаточности собственно пенсионных выплат в части выполнения возлагаемых на них функций - защиты от бедности, компенсации (замещения) заработной платы и обеспечения баланса доходов. Эти индикаторы предложено рассчитывать не только на данных обследований населения, как это преимущественно делается в зарубежной практике, но также и на административных данных, которыми располагает Пенсионный фонд Российской Федерации.
\end{abstract}

Ключевые слова: пенсия, пенсионная система, пенсионные индикаторы, достаточность уровня пенсий, коэффиииент замещения.

Классификация JEL: H55, H75, J32.

DOI: $10.31737 / 2221-2264-2021-52-4-5$

\section{1. Введение}

Индикаторы уровня пенсионного обеспечения (далее - пенсионные индикаторы) необходимы для определения целевых ориентиров пенсионной политики, формирования мер для их реализации, мониторинга достижения целей, а также для сравнения уровня пенсионного обеспечения в различных странах.

1 Статья подготовлена в рамках выполнения научно-исследовательской работы государственного задания РАНХиГС.

Особую благодарность авторы выражают Елене Гришиной, руководителю направления «Уровень жизни и социальная защита» Института социального анализа и прогнозирования РАНХиГС, за ценные замечания и предложения. 
В сравнении с зарубежной практикой набор применяемых в России показателей для оценки уровня пенсионного обеспечения, весьма ограничен и не позволяет адекватным образом оценивать уровень достаточности пенсий и выполнение возлагаемых на них функций, а также проводить корректное сравнение с другими странами.

В качестве одного из основных пенсионных индикаторов в научной литературе и зарубежной практике используется теоретический коэффициент замещения, основанный на модельных оценках для типового гипотетического получателя² ${ }^{2}$ Наряду с ним в зарубежной практике для комплексной оценки достаточности уровня пенсионного обеспечения используются эмпирические индикаторы, расчет которых основан на усреднении статистических данных по соответствующим группам населения. Данная статья посвящена разработке системы эмпирических индикаторов достаточности уровня пенсионного обеспечения применительно к российским условиям.

На основании анализа пенсионных индикаторов, используемых Европейским союзом (ЕС), Организацией экономического сотрудничества и развития (ОЭСР), Международной ассоциацией социального обеспечения и др. (Горлин, Салмина, 2019) в целях сравнения ситуации в России с ситуацией в других странах, предложен ряд эмпирических индикаторов, базирующихся на методологии Европейской комиссии (EK) $\left(\right.$ Eurostat $^{3}$, Eurostat $\left.^{4}\right)$.

На основе предложенных индикаторов даны оценки уровня достаточности пенсий в России в сравнении со странами EC. Расчеты для России проведены на данных «Выборочного наблюдения доходов населения и участия в социальных программах» Росстата 2018 г. (далее - ВНДН-2018), что соответствует зарубежной практике расчета эмпирических показателей, базирующейся на данных выборочных обследований статистических органов соответствующих стран.

В рамках исследования были выявлены дефекты и ограничения международных индикаторов прежде всего для оценки достаточности пенсионных выплат ${ }^{5}$ в рамках системы обязательного пенсионного страхования (ОПС). Поэтому наряду с предложенными индикаторами для межстрановых сравнений был разработан набор индикаторов и методов их оценки, учитывающих специфику системы пенсионного обеспечения в России и уровень достаточности собственно пенсионных выплат в рамках системы ОПС. Индикаторы предлагается рассчитывать не только на данных обследований населения, как это преимущественно делается в зарубежной практике, но также и на адми-

\footnotetext{
${ }^{2}$ Вопросы методологии оценки теоретического коэффициента замещения рассмотрены авторами в статье (Горлин и др., 2020).

3 Eurostat. Employment and social inclusion indicators: Pension (https://ec.europa.eu/eurostat/web/ employment-and-social-inclusion-indicators/social-protection-and-inclusion/pension).

${ }^{4}$ Eurostat - Unit F4. Contract No. 10602.2011.004-2013.548. 'Lot 1: EU-SILC (European Union Statistics on income and Living Conditions): Methodological studies and publications'. Working paper with the description of the 'Income and living conditions dataset'. December 2014. 535 p. (https:/ / circabc.europa.eu/sd/a/038d0218-6ec6-41e1-8b379d293b5fef49/0.\%20Description\%20of\%20Datasets\%20on\%20Income\%20and\%20Living\%20Conditions.pdf).

${ }^{5}$ Здесь и далее, если не оговорено особо, под пенсионной выплатой (в рамках системы ОПС) понимается сумма страховой и накопительной пенсий.
} 
нистративных данных, которыми располагает Пенсионный фонд Российской Федерации.

\section{2. Основные функции пенсий и индикаторы для оценки их достаточности}

Обзор зарубежной литературы и практики (Горлин, Салмина, 2019) позволяет выделить три основные функции, возлагаемые на пенсионные выплаты: снижение рисков бедности, компенсация утрачиваемой заработной платы в связи с прекращением работы при выходе на пенсию в целях сглаживания уровня потребления в пред- и постпенсионном периодах и выполнение неявного договора между поколениями в духе солидарности, имея в виду поддержание приемлемого баланса между доходами работающей части населения и неработающих пенсионеров ${ }^{6}$.

Пенсионные индикаторы должны оценивать, в какой мере размер выплат пенсионерам обеспечивает выполнение соответствующих пенсионных функций.

Здесь необходимо отметить, что, во-первых, требование выполнения этих функций не является абсолютным. Его может обуславливать соблюдение определенных критериев. Например, наличие достаточного стажа, прекращение работы и др. Во-вторых, функциональное назначение пенсий может различаться в зависимости от вида пенсии.

В международной практике в качестве показателя, характеризующего компенсацию пенсией утрачиваемой заработной платы, наиболее часто используется теоретический коэффициент замещения, показывающий, как пенсионный доход в первый год после выхода на пенсию соотносится с заработком перед выходом на пенсию (European Commission, 2012; OECD, 2017; Grech, 2013). Именно для подобного показателя, построенного на модельных оценках, в Конвенциях Международной организации труда задана нижняя допустимая граница - на уровне 40-45\% (Конвенции МОТ № 102, 1287).

Наряду с теоретическим коэффициентом замещения международные организации широко применяют эмпирические индикаторы. При их расчете используются усредненные оценки, получаемые на основе статистических данных (как правило, выборочных обследований и др.) для определенных половозрастных и других групп населения. При оценке ряда эмпирических индикаторов учитываются доходы не только от пенсионных выплат, но и из других источников (более подробное сравнение теоретических и эмпирических индикаторов см. (Горлин, Салмина, 2019)).

\footnotetext{
${ }^{6}$ Указанные формулировки функций, возлагаемых на пенсии, это обобщающая трактовка авторов на основе анализа российских и зарубежных работ, посвященных данной проблематике, например (Draxler, Mortensen, 2009; Holzmann R., Hinz, 2005; OECD, 2011; Social Protection Committee, 2000; Гурвич, Сонина, 2012; Дмитриев и др., 2008; Ляшок, Назаров, Орешкин, 2016; Соловьев, 2014; Соловьев, Герман, 2013; Соловьев, Донцова, 2008).

${ }^{7}$ Конвенция МОТ № 102 (Женева, 1952 г.): «Конвенция о минимальных нормах социального обеспечения». (https://www.ilo.org/wcmsp5/groups/public/--ed_norm/--normes/documents/normativeinstrument/wcms_ c102_ru.pdf), Конвенция МОТ № 128 (Женева, 1967 г.): «Конвенция о пособиях по инвалидности, по старости и по случаю потери кормильца». (https://www.ilo.org/wcmsp5/groups/public/--ed_norm/-normes/ documents/normativeinstrument/wcms_c128_ru.pdf).
} 
Использование, наряду с теоретическими, эмпирических индикаторов обусловлено стремлением преодолеть свойственные теоретическим индикаторам ограничения. Так, например, теоретический коэффициент замещения рассчитывается для гипотетического индивида, обладающего определенными признаками и параметрами, определяющими размер пенсии (продолжительность стажа, уровень заработной платы и др.). В частности, в методологии ЕК данный набор параметров включает работу на полную ставку в возрасте от 25 до 65 лет, полный трудовой стаж длительностью 40 лет и получение среднего по стране уровня заработной платы на протяжении всей карьеры. Очевидно, что такой подход, имеющий определенные достоинства, не может отражать все разнообразие вариантов указанных параметров. В частности, средний житель ЕС выходит на пенсию ранее 65 лет и не отрабатывает 40 лет стажа. Поэтому применение - в дополнение к теоретическим эмпирических показателей создает предпосылки для более адекватной оценки достаточности уровня пенсий.

\section{3. Требования к пенсионным индикаторам}

Основываясь на результатах, изложенных в (Горлин и др., 2020a, 2020б), далее формулируются основные требования и положения, которым должны соответствовать индикаторы достаточности пенсий и методы их оценки.

- Контингент пенсионеров, в отношении которых должны очениваться индикаторы. Функции, возлагаемые на пенсии, обусловлены предположением, что при выходе на пенсию прекращается работа и теряется доход от заработной платы. Поэтому размер пенсии должен быть таков, чтобы доход и соответствующий объем потребления резко не сокращался. Если же после назначения пенсии человек продолжает работать, то его доход не уменьшается, а увеличивается на сумму пенсии и связанных с ней выплат и льгот. Поэтому адекватная оценка достаточности пенсий должна основываться на данных о неработающих пенсионерах.

- Уиитываемые доходы. Оценка достаточности пенсий может предусматривать различные подходы к учету доходов пенсионеров. Если вести речь о выполнении соответствующим видом пенсий возложенных на них функций и оценивать достаточность собственно пенсий, то следует учитывать доход только от этих пенсионных выплат (индикаторы пенсионных выплат), получаемых конкретными пенсионерами.

Однако возможен и больший охват доходов, получаемых пенсионерами. Например, в России получатели страховой пенсии по старости в дополнение к выплатам в рамках ОПС могут получать ряд доплат и льгот, например: доплаты до прожиточного минимума пенсионера; льготы на лекарства, медобслуживание, на санаторно-курортное лечение, проезд на транспорте, льготы по налогам на недвижимость и землю и др. Эти выплаты и льготы в совокупности с пенсионными 
выплатами определяют пенсионный доход. Соответствующие показатели будем называть индикаторами пенсионного дохода. Но в этом случае эти индикаторы будут характеризовать достаточность в целом системы социальной защиты пенсионеров, а не собственно пенсий.

Также определение индикаторов может основываться не на индивидуальных доходах пенсионера, а на его доходах в рамках домохозяйства. С точки зрения оценки бедности это - допустимый подход. Но если стоит задача определить, в какой мере собственно пенсии выполняют ту или иную функцию, то учет доходов других членов домохозяйства и его состава ведет к смещению оценки достаточности пенсий.

- Обеспечение сопоставимости показателей, используемых при определении индикаторов с учетом их разновременности и различий в налоговых режимах.

Для обеспечения корректности определения индикаторов следует:

- приводить разновременные стоимостные показатели к единому моменту времени с учетом нормы приведения, принимаемой, например, в размере индекса потребительских цен;

- учитывать влияние налогов и приравниваемых к ним платежей на доходы.

\section{4. Индикаторы, применяемые в России}

Проведенный анализ (Горлин, Салмина, 2019) показал, что в зарубежной практике применяется достаточно широкий и разнообразный набор пенсионных индикаторов.

В российской практике и научных публикациях (Гурвич, Сонина, 2012; Дмитриев и др., 2008; Ляшок, Назаров, Орешкин, 2016; Соловьев, 2014; Соловьев, Герман, 2013; Соловьев, Донцова, 2008) наибольшее распространение получили два показателя.

Первый из них рассчитывается как отношение среднего размера назначенных пенсий (в том числе пенсий по старости, а также пенсий по старости неработающих пенсионеров) к среднему размеру начисленной заработной платы работников организаций по стране (по Росстату).

Данный показатель, с нашей точки зрения, без должных оснований называется коэффициентом замещения ${ }^{8}$. Он не показывает, в какой мере пенсия компенсирует утрату заработка в связи с прекращением работы при выходе на пенсию. Для такой оценки следует сопоставлять размер пенсии в период после ее назначения (например, год) с заработной платой в предшествующий период. Тогда как при расчете рассматриваемого показателя в числителе стоит средний размер назначенной пенсии всех пенсионеров, а не только тех, кто вышел на пенсию в этом году, а в знаменателе - усредненные данные по заработку всех работников, а не только тех, кто вышел на пенсию в предшеству-

\footnotetext{
${ }^{8}$ Следует отметить, что, хотя в качестве одной из основных целей долгосрочного развития российской пенсионной системы предусмотрено «обеспечение коэффициента замещения трудовой пенсией по старости до 40 процентов утраченного заработка при нормативном страховом стаже и средней заработной плате» (Стратегия долгосрочного развития..., 2020), в Российской Федерации нет общепринятой методологии оценки коэффициента замещения.
} 
ющий период. В данном показателе не учитывается тот факт, что размеры недавно назначенных («новых») пенсий в силу ряда причин ниже пенсий, назначенных несколько лет назад. Поэтому средний размер всех пенсий представляется завышенным (примерно на 10\%) по отношению к новым пенсиям, что ведет к завышению оценки того, в какой мере пенсия компенсирует утрачиваемую заработную плату в связи с выходом на пенсию. Также, если оценивать замещение заработной платы пенсией, следует соотносить величины соответствующих доходов после удержания налога на доходы физических лиц (НДФЛ).

Вместе с тем показатель «Отношение среднего размера назначенных пенсий к среднему размеру начисленной заработной платы» при определенной корректировке может использоваться в качестве пенсионного индикатора. Но его следует интерпретировать как показатель выполнения функции «Обеспечение баланса между доходами пенсионеров и работников».

Второй используемый в России показатель - «Соотношение среднего размера назначенных пенсий и прожиточного минимума пенсионера (ПМП)». При этом величина ПМП принимается в целом по Российской Федерации.

Данный показатель является одним из ключевых индикаторов уровня пенсионного обеспечения, используемых в российской практике планирования и управления пенсионной системой. Так, в качестве цели долгосрочного развития российской пенсионной системы на период до 2030 г. определено обеспечение среднего размера трудовой пенсии по старости не менее 2,5-3,0 ПМП.

Хотя в явном виде это практически нигде не формулируется, но, по всей видимости, данный показатель, определяя уровень пенсий по отношению к границе бедности, оцениваемой величиной ПМП, ориентирован на то, чтобы характеризовать выполнение страховой пенсионной системой функции «Защита от бедности» ${ }^{10}$.

Вместе с тем этот показатель как характеристика выполнения указанной функции имел ранее и продолжает иметь ряд дефектов ${ }^{11}$ :

- в ряде работ приведена обоснованная критика действовавшего до 2021 г. подхода к измерению бедности на основе концепции абсолютной бедности и соответствующим образом определяемого показателя прожиточного минимума (например, (Бобков и др., 2019; Корнейчук, 2017; Ржаницына, 2019));

- подход к оценке достаточности уровня пенсий с использованием абсолютной границы бедности, определяемой прожиточным минимумом, не соответствовал методологии, применяемой в большинстве стран, базирующейся на концепции относительной монетарной бедности (European Commission, 2018);

${ }^{9}$ Стратегия долгосрочного развития пенсионной системы Российской Федерации (утв. Распоряжением Правительства РФ от 25 декабря 2012 г. № 2524-p) от 25.12.2012 г. (https://base.garant.ru/70290226/).

10 Здесь следует отметить, что возложение на страховую пенсионную систему функции защиты от бедности, с нашей точки зрения, не является бесспорным. Вместе с тем желательно, чтобы при достаточно длительном страховом стаже размер пенсий превышал порог бедности.

${ }^{11}$ Статья была подготовлена в первой половине 2020 г. до изменения с 2021 г. подхода к определению прожиточного минимума, в связи с чем первый и второй из перечисленных дефектов в определенной мере ослабляются. 
- использование единого ПМП в целом по РФ не учитывает существенных региональных различий уровней доходов, пенсий и ПМП и др.;

- в международной практике при оценке выполнения пенсией функции защиты от бедности используются показатели, характеризующие риск бедности и ее глубину; отношение среднего размера пенсии к ПМП не характеризует ни того, ни другого;

- показатель «Средний размер назначенных пенсий» не учитывает выплат по накопительной пенсии, а также других доплат и льгот, получаемых пенсионерами в соответствии с действующим законодательством;

- средний размер пенсий корректнее определять только по данным о неработающих пенсионерах, так как именно в отношении них пенсия должна выполнять функцию защиты от бедности.

Однако, несмотря на отмеченные дефекты, использование показателя «Соотношение среднего размера назначенных пенсий и ПМП», учитывая достаточную стабильность структуры потребительской корзины, заложенной в расчет ПМП, позволяет оценить динамику покупательной способности среднего размера пенсий с учетом изменений цен на продукты и услуги, специфичные именно для пенсионеров, а не для населения в целом, как при расчете показателя ИПЦ ${ }^{12}$. Таким образом, применяемый в России инструментарий оценки пенсионных показателей крайне ограничен. Его методология существенно отличается от зарубежных стран и не позволяет адекватным образом оценивать уровень достаточности пенсий и проводить корректные межстрановые сравнения.

\section{5. Эмпирические пенсионные индикаторы для межстрановых сравнений}

На основании анализа международной практики определения пенсионных индикаторов (Горлин, Салмина, 2019) для сопоставления России с другими странами предлагается использовать индикаторы, основывающиеся на методологии ЕК, с нашей точки зрения, наиболее развитой и представительной.

Определения и методология расчета предлагаемых индикаторов представлены в табл. 1.

В качестве основного индикатора выполнения в России пенсиями функции защиты от бедности для межстрановых сравнений пред-

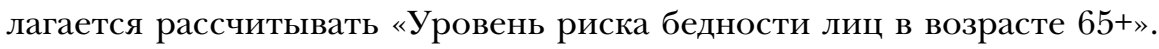
Вообще говоря, данный индикатор не оценивает риска того, что у лиц в возрасте $65^{+}$размер их пенсионной выплаты находится ниже границы бедности и, соответственно, насколько пенсия выполняет функцию защиты от бедности. Он характеризует риск бедности лиц старших возрастов в рамках домохозяйства с учетом его состава и всех доходов.

\footnotetext{
${ }^{12}$ В связи с изменением подхода к определению ПМП данное положение, возможно, подлежит переоценке.
} 
таблица 1

Эмпирические пенсионные индикаторы, предлагаемые для межстрановых сравнений ${ }^{13}$

\begin{tabular}{|c|c|c|}
\hline Наименование & Назначение & Методика расчета \\
\hline \multicolumn{3}{|c|}{ Функция «Защита от бедности» } \\
\hline $\begin{array}{l}\text { Уровень риска бед- } \\
\text { ности лиц в возрасте } \\
65 \text { лет и старше } \\
\left.\text { (далее }-65^{+}\right)\end{array}$ & $\begin{array}{l}\text { Показывает риск отно- } \\
\text { сительной бедности } \\
\text { лиц в возрасте } 65+\text { с уче- } \\
\text { том доходов из всех } \\
\text { источников и в рамках } \\
\text { домохозяйства }\end{array}$ & $\begin{array}{l}\text { Рассчитывается как доля людей в возрасте } 65+\text { с экви- } \\
\text { валентным располагаемым доходом ниже относитель- } \\
\text { ного порога бедности, принимаемого на уровне } 60 \% \\
(50 \text { и } 40 \%) \text { от медианного эквивалентного располагае- } \\
\text { мого дохода по всему населению. Дополнительно дела- } \\
\text { ются расчеты для границ } 60+, 70+\text { в том числе с раз- } \\
\text { бивкой по полу }\end{array}$ \\
\hline $\begin{array}{l}\text { Относительная } \\
\text { медиана порога бед- } \\
\text { ности лиц в возрасте } \\
65^{+}\end{array}$ & $\begin{array}{l}\text { Характеризует относи- } \\
\text { тельную глубину бедности } \\
\text { среди лиц в возрасте } 65^{+} \\
\text {с учетом доходов из всех } \\
\text { источников и в рамках } \\
\text { домохозяйства }\end{array}$ & $\begin{array}{l}\text { Рассчитывается как разница между относительным } \\
\text { порогом бедности лиц в возрасте } 65^{+}, \text {принимаемым } \\
\text { на уровне } 60 \% \text { от медианного эквивалентного рас- } \\
\text { полагаемого дохода лиц в возрасте } 65^{+} \text {и медианным } \\
\text { эквивалентным располагаемым доходом лиц в воз- } \\
\text { расте } 65^{+}, \text {имеющих доход ниже относительного } \\
\text { порога риска бедности, выраженная в процентах от } \\
\text { относительного порога бедности. Дополнительно } \\
\text { делаются расчеты для границ } 60+, 75^{+} \text {, в том числе } \\
\text { с разбивкой по полу }\end{array}$ \\
\hline \multicolumn{3}{|c|}{ Функция «Компенсация (замещение) заработной платы» } \\
\hline $\begin{array}{l}\text { Коэффициент } \\
\text { агрегированного } \\
\text { замещения без учета } \\
\text { других социальных } \\
\text { выплат }\end{array}$ & $\begin{array}{l}\text { Характеризует соотноше- } \\
\text { ние размера пенсионной } \\
\text { выплаты лиц в возрасте } \\
65-74 \text { лет и заработка лиц } \\
\text { в возрасте 50-59 лет без } \\
\text { учета других социальных } \\
\text { пособий, кроме пенсий }\end{array}$ & $\begin{array}{l}\text { Рассчитывается как отношение медианной вели- } \\
\text { чины валового размера пенсионной выплаты (вклю- } \\
\text { чает выплаты страховой, накопительной и социаль- } \\
\text { ной пенсий, других пенсий по гособеспечению) лиц } \\
\text { в возрасте } 65-74 \text { лет к медианной величине валового } \\
\text { заработка лиц в возрасте } 50-59 \text { лет (без учета других } \\
\text { социальных пособий, кроме пенсий)*, в том числе } \\
\text { с разбивкой по полу }\end{array}$ \\
\hline \multicolumn{3}{|c|}{ Функция «Обеспечение баланса доходов» } \\
\hline $\begin{array}{l}\text { Коэффициент отно- } \\
\text { сительного уровня } \\
\text { пенсий (benefit } \\
\text { ratio) }\end{array}$ & $\begin{array}{l}\text { Характеризует соотноше- } \\
\text { ние размера пенсионной } \\
\text { выплаты и заработной } \\
\text { платы в стране в целом }\end{array}$ & $\begin{array}{l}\text { Рассчитывается как отношение средней величины } \\
\text { валового размера пенсионной выплаты (включает } \\
\text { выплаты страховой, накопительной и социальной } \\
\text { пенсий, других пенсий по гособеспечению) и средней } \\
\text { заработной платы по стране }\end{array}$ \\
\hline $\begin{array}{l}\text { Коэффициент меди- } \\
\text { анного относитель- } \\
\text { ного дохода }\end{array}$ & $\begin{array}{l}\text { Характеризует соотноше- } \\
\text { ние эквивалентных рас- } \\
\text { полагаемых доходов лиц } \\
\text { в возрасте } 65+\text { и лиц в воз- } \\
\text { расте } 65-\end{array}$ & $\begin{array}{l}\text { Рассчитывается как отношение медианного размера } \\
\text { эквивалентного располагаемого дохода лиц в воз- } \\
\text { расте } 65^{+} \text {к медианному эквивалентному распола- } \\
\text { гаемому доходу лиц в возрасте } 65-\text {. Дополнительно } \\
\text { делаются расчеты для границы } 60+\text { в том числе с раз- } \\
\text { бивкой по полу }\end{array}$ \\
\hline
\end{tabular}

* В отношении данного показателя следует отметить следующее. Повышение пенсионного возраста в течение переходного периода (до 2028 г.) будет определенно влиять на занятость лиц в предпенсионных возрастах, прежде всего женщин, и соответственно на размеры заработной платы и пенсий, учитываемых при расчете индикатора. Но, с нашей точки зрения, это не создает значимых препятствий для использования этого показателя для проведения межстрановых сравнений по методологии Европейской комиссии.

Примечание. Таблица включает основные индикаторы, предусмотренные методологией Европейской комиссии (ЕК). Также предусматривается определение тех дополнительных индикаторов ЕК, которые являются модификацией основных показателей для других возрастных когорт, пола и различных границ уровня бедности. При этом не включены дополнительные показатели, которые не связаны с оценкой выполнения функций, возлагаемых на пенсии. В частности, в таблице нет показателя неравенства.

Источник: составлено авторами на основе методологии ЕК (Eurostat. Employment and social inclusion indicators; Eurostat, 2014).

13 Здесь и далее в статье для однозначности, если не оговорено особо, значения всех показателей доходов (заработная плата, компоненты пенсионных выплат), учитываемых при расчете эмпирических индикаторов, считаются валовыми, т.е. до удержания НДФЛ. 
Аналогичная ситуация с индикатором «Относительная медиана порога бедности лиц в возрасте $65^{+} »$, оценивающим, насколько медианное значение эквивалентного располагаемого дохода лиц в возрасте $65^{+}$с доходом ниже относительной границы бедности для лиц в этих возрастах, меныше этой границы (в процентах от нее). Этот индикатор характеризует глубину бедности. Но он представляет собой не столько характеристику достаточности пенсий, сколько один из показателей, оценивающих положение лиц в возрасте $65^{+}$с учетом всех доходов и состава домохозяйств, в которых они проживают.

Но поскольку в России для домохозяйств пенсионеров, согласно нашим оценкам, полученным на данных ВНДН-2018, на долю пенсий приходится более $70 \%$ денежных доходов, а с учетом других социальных пособий пенсионерам - более $80 \%$, то указанные два индикатора с определенными оговорками можно расценивать как релевантные для оценки выполнения пенсиями функции защиты от бедности.

Для оценки выполнения функции компенсации (замещения) заработной платы предлагается использовать индикатор «коэффициент агрегированного замещения». Следует отметить, что, характеризуя соотношение пенсий лиц в возрасте 65-74 лет и заработной платы лиц в возрасте 50-59 лет (медианных значений), с нашей точки зрения, данный коэффициент в общем случае не является релевантной оценкой степени компенсации пенсией утрачиваемого заработка. Но вместе с тем он является в настоящее время наилучшим эмпирическим индикатором замещения утрачиваемой заработной платы пенсией для проведения межстрановых сравнений.

Для оценки выполнения функции баланса доходов пенсионеров и работников - из индикаторов ЕК предлагаются:

- коэффициент относительного уровня среднего размера пенсий, являющийся практически аналогом соответствующего индикатора, используемого в российской практике, со всеми его плюсами и недостатками (см. раздел «Индикаторы, применяемые в России»).

- коэффициент медианного относительного дохода, который только с определенными оговорками можно рассматривать в качестве измерителя баланса между доходами пенсионеров и работников. Он лишь косвенно характеризует данную функцию, так как сравнивает доходы пенсионеров $65^{+}$не только с работающим населением, но и со всеми лицами 65-. Кроме того, в его числитель включаются все доходы лиц $65^{+}$, а не только пенсии.

В следующем разделе представлены результаты расчетов эмпирических индикаторов по России (на данных ВНДН-2018), предложенных для межстрановых сравнений (см. разд. 6), в сопоставлении со странами EC. 


\section{6. Результаты расчетов индикаторов для межстрановых сравнений}

\section{1. Индикаторы функции защиты от бедности}

Результаты расчетов риска бедности лиц в возрасте $65^{+}$ в России в сопоставлении с европейскими странами приведены на рис. 1. Расчеты выполнены для различных уровней порога бедности $-40,50$ и $60 \%$ медианного эквивалентного располагаемого дохода.

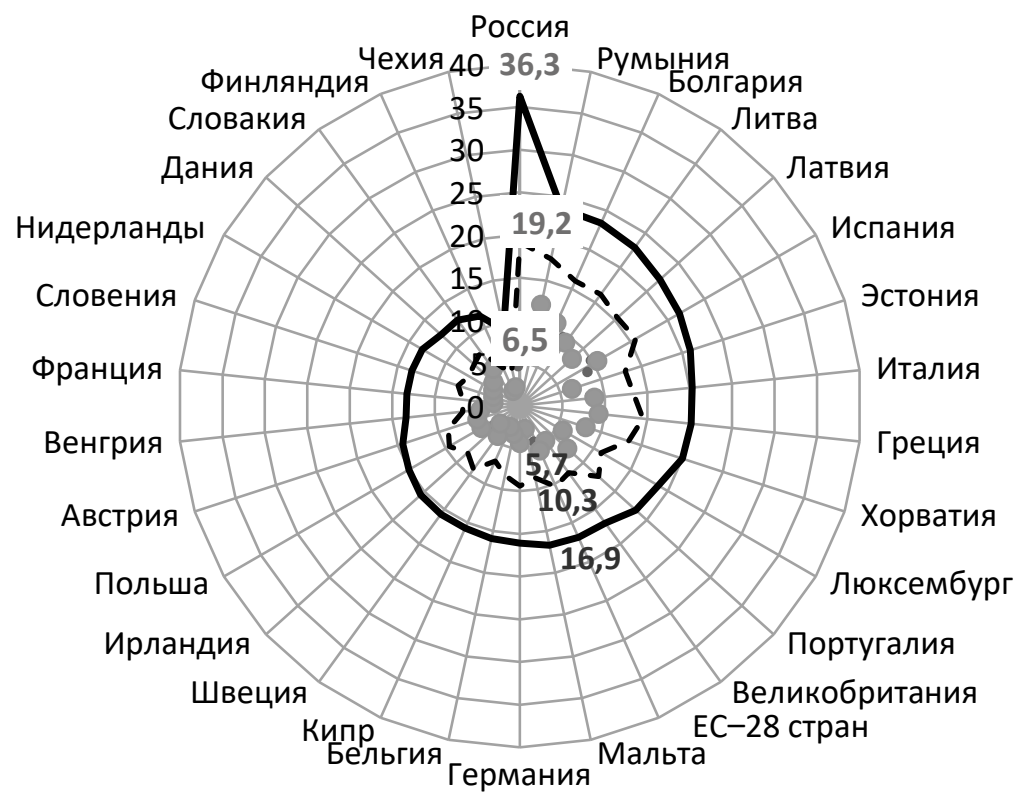

-. - Порог риска бедности - 40\% медианного эквивалентного располагаемого дохода

Puc. 1

Сравнение уровня риска бедности лич в возрасте 65+ в России и в странах EC (2017 г.), \%

Источник: Евростат, оценки по России - расчеты авторов на данных ВНДН-2018 ${ }^{14}$.

Если граница бедности принимается на уровне $40 \%$ медианного әквивалентного располагаемого дохода для всего населения, что наиболее приближено к ПМП, принимаемому в качестве границы бедности в России, то уровень российских пенсий с точки зрения защиты от бедности примерно соответствует среднеевропейскому уровню.

Но по мере повышения границы бедности и приближения к европейским стандартам ( $60 \%$ медианного дохода), предполагающим, что уровень доходов пенсионеров должен обеспечить большие расходы на здравоохранение, содержание жилья, автотранспорт, поддержание социальных контактов, культурный досуг и др., отставание России становится все более значительным.

Отметим, что относительно высокий уровень риска бедности среди лиц в возрасте $65^{+}$по сравнению со странами ЕС может объясняться не только более низкими размерами пенсионных выплат, но

14 Здесь и далее оценки для стран ЕС приведены за 2017 г. по данным Евростата. Для России расчеты авторов сделаны на данных ВНДН-2018. 
и быть следствием особой структуры домохозяйств. В России по сравнению с европейскими странами более распространены многопоколенные домохозяйства. При этом, согласно российской статистике, уровень бедности в домохозяйствах, в которых пенсионеры живут с более молодыми членами семьи, выше, чем в домохозяйствах, полностью состоящих из лиц старшего возраста.

Оценки относительной медианы порога бедности для лиц старше 65 лет, характеризующие глубину бедности, в России и странах ЕС представлены на рис. 2.

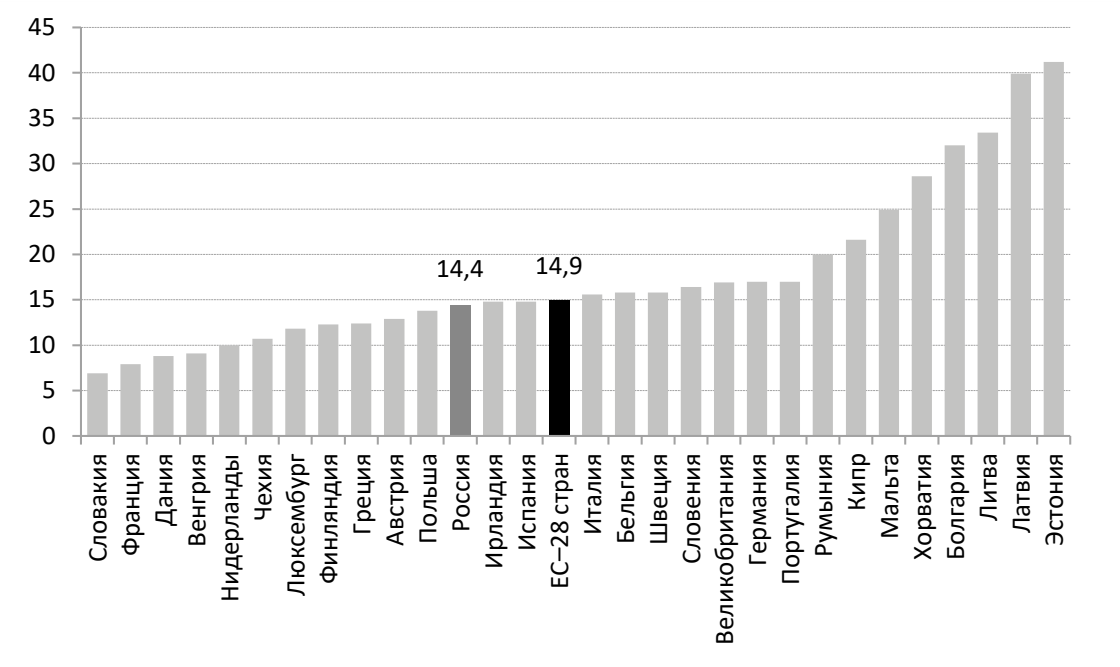

Pис. 2

Относительная медиана порога бедности лич в возрасте 65+ в России и в странах EC (в 2017 r.)

Примечание. Согласно методологии ЕК порог риска бедности принимается на уровне $60 \%$ медианного эквивалентного располагаемого дохода.

Источник: Евростат; оценки по России - расчеты авторов на данных ВНДН-2018 и официальной отчетности Росстата.

Примерное равенство оценок глубины бедности лиц в возрасте $65^{+}$в России $(14,4 \%)$ и среднего уровня по странам ЕС $(14,9 \%)$ при относительно более высоких рисках бедности, по всей видимости, может быть объяснено более широким применением в России инструментов, выравнивающих размеры доходов лиц 65+ (фиксированная выплата к страховой пенсии, доплаты до ПМП, другие социальные выплаты пенсионерам), которые, снижая глубину бедности, не столь значимо уменьшают ее риск.

6.2. Индикатор «Компенсация (замещение) заработной платы»

В соответствии с расчетами на данных ВНДН-2018 значение коэффициента агрегированного замещения в России равно 58\% и совпадает со средним по 28 странам ЕС (рис. 3). 


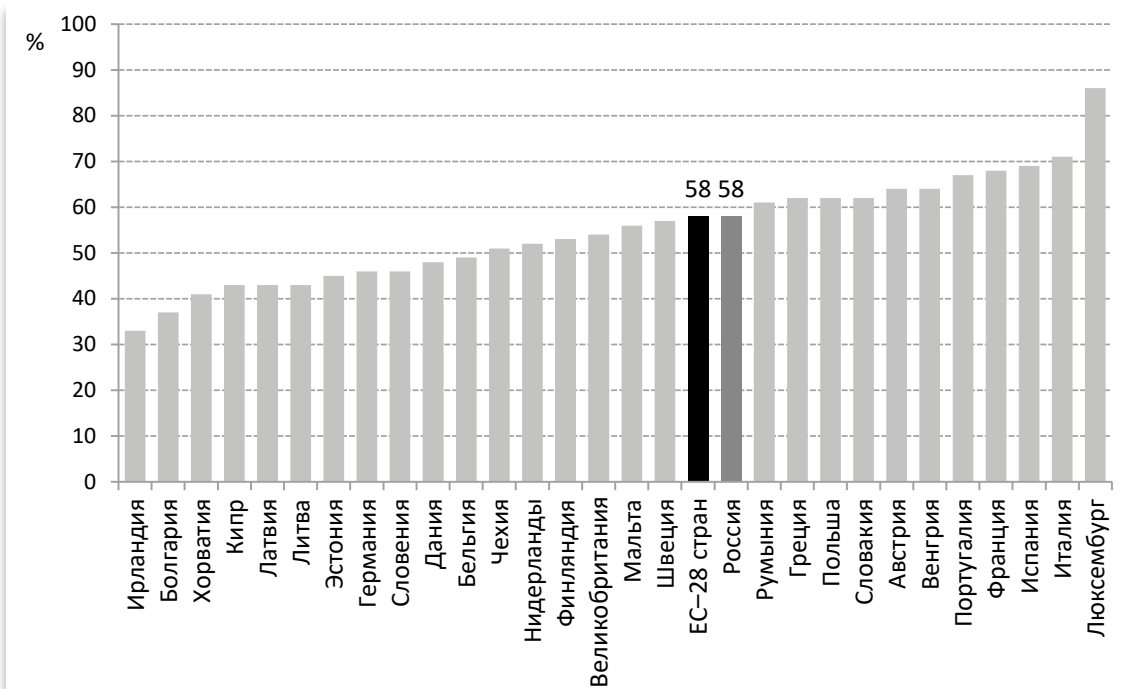

Pис. 3

Коэффичиент агрегированного замещения в России и странах EC (2017 г.)

Примечание. Данные по России не включают произведенную в январе 2017 г. единовременную денежную выплату в размере 5 тыс. рублей, назначенную в соответствии с Федеральным законом от 22.11.2016 г. № 385-ФЗ.

Источник: Евростат, оценки по России - расчеты авторов на данных ВНДН-2018.

Отметим, что есть определенные сложности, затрудняющие прямое сопоставление данного коэффициента в России и странах ЕС. При более низком пенсионном возрасте значительная часть населения начинает получать пенсию до 60 лет. Получение пенсии существенно влияет на решение о продолжении оставаться занятым по достижении пенсионного возраста: часть населения становится экономически неактивной или переходит на другую, нижеоплачиваемую работу. В результате селективности занятости после достижения пенсионного возраста оценка коэффициента агрегированного замещения оказывается в России смещенной в большую сторону. Вместе с тем надо понимать, что по мере повышения пенсионного возраста это смещение должно снизиться.

\section{3. Индикаторы баланса доходов}

На рис. 4 представлено сравнение значения индикатора «Баланса доходов» в России и в странах ЕС. По соотношению средних значений пенсии и заработной платы ситуация в России хуже средних показателей по странам ЕС (43\%).

Величина коэффициента относительного уровня пенсий, рассчитанная на данных ВНДН-2018, равна 38\%. Значение публикуемого Росстатом показателя «Соотношение среднего размера назначенных пенсий со средним размером начисленной заработной платы» в 2017 г. равно $32,9 \%$. 


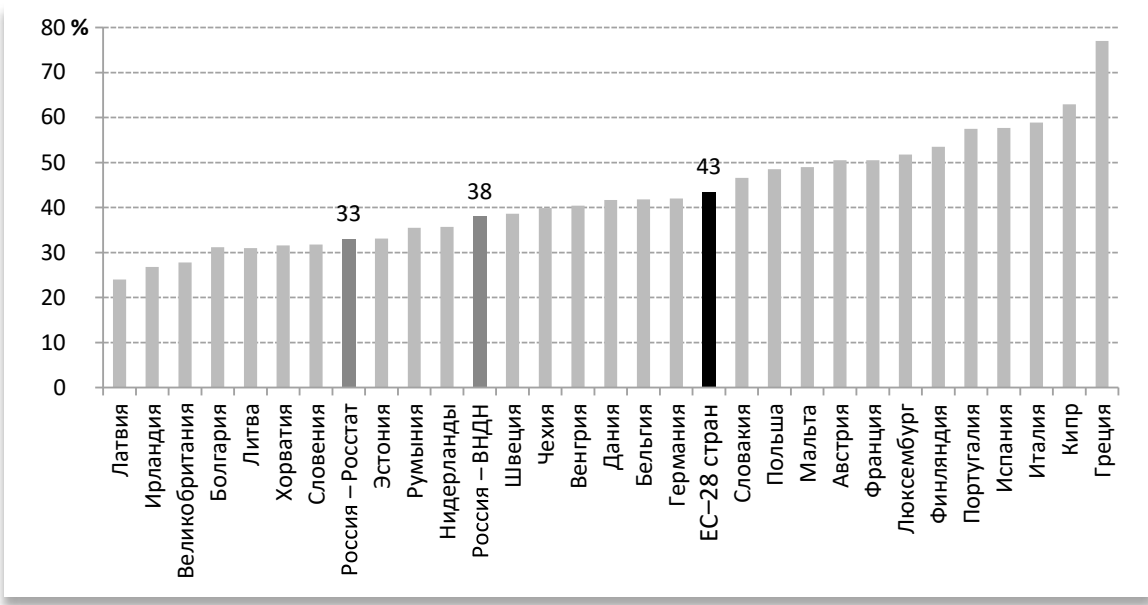

Puc. 4

Коэффииент относительного уровня пенсий в России и в странах ЕC

Источник: Евростат; оценки по России - расчеты авторов на данных ВНДН-2018 и официальные оценки Росстата.

Отличие полученного результата от оценки Росстата связано с тем, что получаемая на основе на данных ВНДН-2018 по всей совокупности занятых средняя заработная плата ниже, а средняя пенсия - выше, чем по Росстату. Это можно объяснить тем, что величина средней заработной платы по Росстату учитывает данные только по организациям, что завышает оценку заработной платы и снижает оценку соотношения пенсий и заработных плат. С другой стороны, величина пенсий по Росстату не включает пенсии военнослужащих и отдельные виды накопительных пенсий, что занижает оценку пенсий и показатель Росстата.

Расчетная величина коэффициента медианного относительного дохода для России равна 0,73 при среднем уровне по ЕС - 0,92 (рис. 5). Различия данных показателей в некоторой мере могут отражать разную

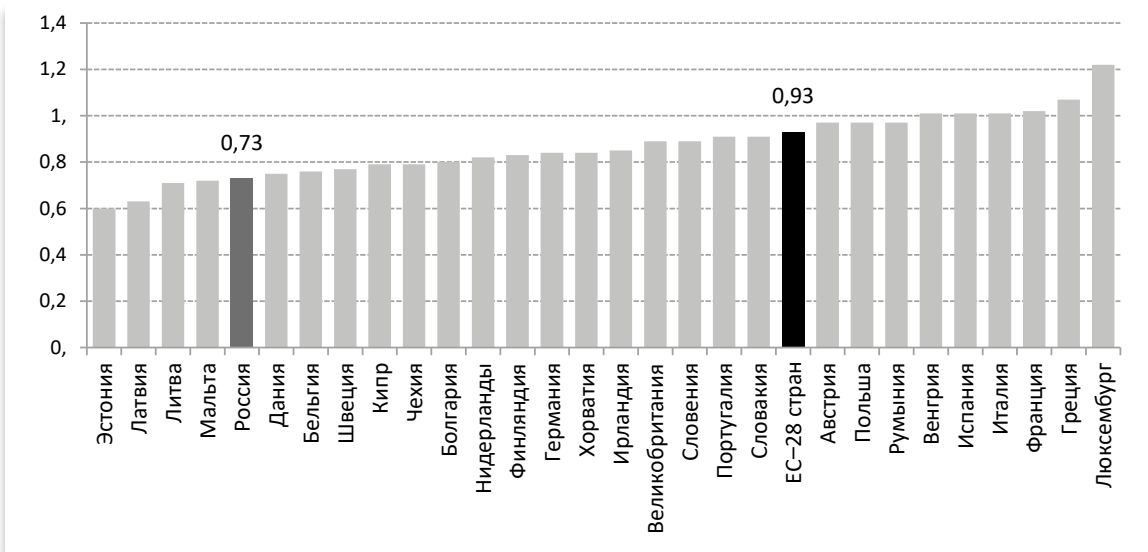

Pис. 5

КоэФфичиент медианного относительного дохода в России и в странах ЕC

Источник: Евростат; оценки по России - расчеты авторов на данных ВНДН-2018. 
роль семьи (домохозяйства) в поддержании достойного уровня жизни пенсионеров, исторически сложившуюся в отдельных странах.

Относительно низкое значение рассмотренных выше двух индикаторов для России свидетельствует о сравнительно большем (в сравнении с европейскими странами) дисбалансе доходов пенсионеров - по сравнению со всем населением, и в частности лицами трудоспособного возраста.

\section{7. Предлагаемая методология оценки индикаторов достаточности пенсий}

Как было отмечено выше, пенсионным индикаторам, применяемым международными организациями, свойственны определенные ограничения в части их использования для управления российской системой ОПС.

В связи с этим нами была разработана методология расчета эмпирических пенсионных индикаторов применительно к специфике системы ОПС. Основное предназначение этих индикаторов - формализация целевых ориентиров пенсионной политики, формирование мер их реализации и мониторинг достижения целей.

Принципиальная отличительная особенность предлагаемого подхода к оценке эмпирических индикаторов состоит в следующем.

Во-первых, эти индикаторы ориентированы прежде всего на оценку достаточности собственно пенсионных выплат в части выполнения возлагаемых на них функций.

Во-вторых, практически все применяемые ранее подходы к оценке эмпирических пенсионных индикаторов основывались на усреднении данных о размерах пенсионных выплат, пенсионных доходов и других параметров, необходимых для определения соответствующего индикатора по лицам, входящим в специальным образом сформированную выборку из определенной части населения (пенсионеров, работников). При этом исходная информация для их расчета показателей преимущественно определяется на основе данных официальной статистики, исследований рынка труда, социологических обследованиях населения.

С нашей точки зрения, информация, необходимая для определения эмпирических индикаторов, применительно к российским условиям может быть получена на основе административных данных, прежде всего аккумулируемых в Пенсионном фонде РФ и, частично, в Федеральной налоговой службе. Информационные системы этих ведомств содержат все данные о пенсиях, заработной плате, других выплатах и доходах, а также другую информацию, требующуюся для оценки пенсионных индикаторов.

Поэтому нерационально определять индикаторы, так как это делается в настоящее время, т.е. преимущественно на основе данных исследований рынка труда, социологических обследований населения 
и др. Во-первых, это - дополнительные затраты, во-вторых, эти данные менее точны и представительны, так как имеют выборочный характер по сравнению с административными данными. Зачем оперировать выборкой, когда есть генеральная совокупность?

Конечно, ключевым условием реализуемости предлагаемого подхода является допущение, что указанные организации будут предоставлять соответствующую информацию. Но на наш взгляд, это - их обязанность, так как эти ведомства функционируют за счет средств плательщиков страховых взносов и налогов и должны предоставлять обществу аккумулируемую информацию, естественно, с учетом ограничений, связанных с защитой персональных данных и государственной тайной. Предлагаемая методология расчета пенсионных индикаторов не нарушает этих ограничений. Вместе с тем, понимая ограничения в доступности и возможности использовать административные данные, в течение определенного переходного периода предлагается рассчитывать описанные выше индикаторы на данных ВНДН с соответствующими корректировками методологии.

В табл. 2 приведены пенсионные индикаторы для оценки достаточности пенсионных выплат в рамках российской системы ОПС и методология их определения. Рассмотрение результатов расчетов этих индикаторов выходит за рамки настоящей статьи.

\section{Таблица 2}

Предлагаемые пенсионные индикаторы для оценки достаточности пенсионных выплат применительно к условиям российской системы ОПС

\begin{tabular}{|l|l|l|l|l|}
\hline \multicolumn{1}{|c|}{$\begin{array}{l}\text { Наименование } \\
\text { индикатора }\end{array}$} & \multicolumn{1}{|c|}{ Назначение } & \multicolumn{2}{|c|}{ Расчет } & \multicolumn{1}{|c|}{ Комментарий } \\
\hline \hline \multicolumn{1}{|c|}{ Функция защиты от бедности } \\
\hline $\begin{array}{l}\text { Риск бедности } \\
\text { по пенсионной } \\
\text { выплате* }\end{array}$
\end{tabular}


Окончание таблицы 2

\begin{tabular}{|c|c|c|c|}
\hline $\begin{array}{c}\text { Наименование } \\
\text { индикатора }\end{array}$ & Назначение & Расчет & Комментарий \\
\hline \multicolumn{4}{|c|}{ Функция компенсации (замещения) заработной платы } \\
\hline $\begin{array}{l}\text { Эмпирический } \\
\text { коэффициент } \\
\text { замещения }\end{array}$ & $\begin{array}{l}\text { Характеризует, в какой } \\
\text { мере собственно пен- } \\
\text { сионные выплаты обе- } \\
\text { спечивают выполнение } \\
\text { данной функции в отно- } \\
\text { шении неработающих } \\
\text { пенсионеров как отдель- } \\
\text { ных индивидов (без } \\
\text { учета доходов и состава } \\
\text { домохозяйства) }\end{array}$ & $\begin{array}{l}\text { Оценивает отношение } \\
\text { размера пенсионной } \\
\text { выплаты в месяц, следу- } \\
\text { ющий за первым после } \\
\text { назначения пенсии про- } \\
\text { должительным (не менее } \\
\text { шести месяцев) прекра- } \\
\text { щением работы, к сред- } \\
\text { нему размеру заработной } \\
\text { платы (после удержания } \\
\text { НДФЛ) за } 36 \text { месяцев до } \\
\text { начала получения страхо- } \\
\text { вой пенсии по старости** }\end{array}$ & $\begin{array}{l}\text { Может рассчитываться допол- } \\
\text { нительно по группам пенсио- } \\
\text { неров, различающихся полом, } \\
\text { страховым стажем, уровнем } \\
\text { заработной платы }\end{array}$ \\
\hline \multicolumn{4}{|c|}{ Функция обеспечения баланса доходов } \\
\hline $\begin{array}{l}\text { Коэффициент } \\
\text { относительного } \\
\text { уровня пенсион- } \\
\text { ных выплат }\end{array}$ & $\begin{array}{l}\text { Характеризует соотно- } \\
\text { шение размера пенси- } \\
\text { онной выплаты и сред- } \\
\text { ней заработной платы } \\
\text { в стране в целом. }\end{array}$ & $\begin{array}{l}\text { Рассчитывается как отно- } \\
\text { шение размеров пенсион- } \\
\text { ной выплаты и средней } \\
\text { заработной платы по } \\
\text { стране }\end{array}$ & $\begin{array}{l}\text { Рассчитывается: } \\
\text { • в отношении неработающих } \\
\text { пенсионеров, получающих } \\
\text { страховую пенсию; } \\
\text { • может дополнительно рас- } \\
\text { считываться для медианных } \\
\text { величин пенсионных выплат } \\
\text { и заработных плат }\end{array}$ \\
\hline
\end{tabular}

* До 2020 г. включительно ПМП был показателем, характеризующим абсолютный уровень бедности. Однако с 2021 г. он рассчитывается в привязке не к потребительской корзине, а к медианному доходу населения. Таким образом, ПМП теперь является границей относительной бедности. Поэтому если ранее имело смысл рассчитывать как абсолютные, так и относительные показатели, то теперь возможность расчета на основе абсолютной границы бедности отсутствует.

** Принятие продолжительности периода, предшествующего выходу на пенсию, за который определяется средний размер заработной платы, для расчета коэффициента замещения пенсионной выплатой в размере 36 месяцев обусловлено следующими соображениями. Этот период должен быть таким, чтобы можно было получить более устойчивую и адекватную оценку дохода, к которому адаптировалось потребление человека перед выходом на пенсию. Другими словами, этот период должен быть, с одной стороны, достаточно продолжительным, чтобы снизить влияние случайных факторов (снижение заработной платы в связи с временным прекращением работы, болезнью и др.), с другой стороны, временные отрезки этого периода не должны значительно отстоять от периода начала получения пенсии, с тем чтобы структура и соответствующий объем потребления в пред- и постпенсионные периоды примерно корреспондировали между собой. Исходя из этих соображений, мы полагаем, что продолжительность периода в 12 месяцев недостаточна. 360 месяцев (10 лет), по всей видимости, слишком длительная, тем более для условий высокой волатильности российских характеристик доходов и других факторов. Поэтому 36 месяцев (хотя возможен вариант и 60 месяцев) нам представляется наиболее сбалансированным периодом.

Источник: составлено авторами.

\section{8. Заключение}

Индикаторы достаточности уровня пенсионного обеспечения - необходимый инструментарий для формирования и реализации әффективной пенсионной политики. Они должны характеризовать выполнение основных, возлагаемых на пенсии, функций: замещения утрачиваемой заработной платы при выходе на пенсию; снижение рисков бедности среди пенсионеров и поддержание договора между поколениями в духе солидарности за счет обеспечения приемлемого 
баланса между доходами работающей части населения и неработающих пенсионеров. Для характеристики каждой из этих трех функций предложены соответствующие индикаторы, как для проведения межстрановых сравнений, базирующиеся на методологии ЕК, так и разработанные авторами специально для России с учетом специфики системы ОПС.

Представленные в статье результаты расчетов әмпирических показателей достаточности уровня пенсий в России в сравнении со странами ЕС продемонстрировали следующее.

Уровень риска бедности пенсионеров в России в сравнении со странами ЕС существенно зависит от принимаемого для оценки порога бедности. При пороге бедности в $40 \%$ медианного располагаемого дохода по всему населению, что наиболее близко по значению к ПМП, являющемуся гарантированным уровнем дохода для российских пенсионеров, - показатели России находятся примерно на уровне средних показателей по 28 странам ЕС. Однако с увеличением порога российские оценки бедности возрастают в большей мере, чем в европейских странах. При пороге в $60 \%$, который практически является стандартом для оценки бедности в европейских странах, риск бедности российских пенсионеров в возрасте 65 лет и старше превышает уровень всех европейских стран.

При этом относительная глубина бедности лиц в возрасте $65^{+}$ несколько ниже среднего уровня по странам EC-28.

Коэффициент замещения пенсией заработной платы в России (коэффициент агрегированного замещения, рассчитываемый на основе медианных значений пенсий и зарплат) соответствует среднему уровню по странам EC. С точки зрения обеспечения баланса между доходами пенсионеров и работников, оцениваемому как соотношение средних значений пенсии и заработной платы, ситуация в России несколько хуже среднего уровня по странам EC-28.

Важно подчеркнуть, что рассмотренные выше индикаторы предназначены для проведения межстрановых сравнений. Это относительные показатели, и уровень их значений во многом связан с общим сравнительно более низким уровнем доходов россиян. При этом они основываются на эквивалентных доходах в рамках домохозяйства, что не позволяет в чистом виде оценить роль собственно пенсионных выплат.

Для оценки достаточности пенсионных выплат применительно к условиям российской системы ОПС в статье предложена система эмпирических индикаторов и методология их расчета. Отличительная особенность предложенной методологии состоит в том, что в качестве информационной основы для расчета индикаторов предложено в дополнение к данным органов государственной статистики использовать административные данные, аккумулируемые в информационных системах Пенсионного фонда Российской Федерации. 


\section{ЛИТЕРАТУРА / REFERENCES}

Бобков В.Н., Гулюгина А.А., Одинцова Е.В., Сафронова А.М. (2019). Социально приемлемая потребительская корзина / / Уровень жизни населения регионов России. № 2 (212). C. 8-26. [Bobkov V.N., Gulyugina A.A., Odintsova E.V., Safronova A.M. (2019). Socially acceptable consumer basket. Living Standards of the Population in the Regions of Russia, 2 (212), 8-26 (in Russian).]

Горлин Ю.М., Ляшок В.Ю., Салмина А.А. (2020а). Коэффициент замещения как инструмент анализа и прогнозирования пенсионной системы / / Bonpocы экономики. № 12. C. 80-103. DOI: 10.32609/0042-8736-2020-12-80-103 [Gorlin Yu.M., Lyashok V.Yu., Salmina A.A. (2020a). Replacement rate as an instrument of analysis and forecasting of pension system. Voprosy Ekonomiki, 12, 80-103 (in Russian).]

Горлин Ю.М., Ляшок В.Ю., Салмина А.А., Федоров В.В. (2020б). Индикаторы уровня пенсионного обеспечения в системе обязательного пенсионного страхования: методология и сравнение России с другими странами // Препринт РАНХиГС. № 032011. 100 с. [Gorlin Yu.M., Lyashok V.Yu., Salmina A.A., Fedorov V.V. (2020b). Indicators of the level of pension provision in the mandatory pension insurance system: Methodology and comparison of Russia with other countries. Preprint RANEPA, 032011, 100 p. (in Russian).]

Горлин Ю.М., Салмина А.А. (2019). Сравнительный анализ международного опыта применения индикаторов уровня пенсионного обеспечения // Вестник Института экономики Российской академии наук. № 5. С. 114-131. [Gorlin Yu.M., Salmina A.A. (2019). Comparative analysis of international experience in applying indicators of the level of pension provision. Bulletin of the Institute of Economics RAS, 5, 114-131 (in Russian).]

Гурвич Е., Сонина Ю. (2012). Микроанализ российской пенсионной системы / / Вопросы экономики. № 2. C. 27-51. [Gurvich E., Sonina Yu. (2012). Microanalysis of the Russia's Pension System. Voprosy Ekonomiki, 2, 27-51 (in Russian).]

Дмитриев М.Э., Дробышевский С.М., Михайлов Л.В. и др. (2008). Можно ли повысить пенсии до 40\% заработной платы? / / Экономическая политика. № 3. C. 26-36. [Dmitriev M.E., Drobyshevsky S.M., Mikhailov L.V. et al. (2008). Is it possible to increase pensions to $40 \%$ of wages? Economic Policy. Journal for Professionals, 3, 26-36 (in Russian).]

Корнейчук Б.В. (2017). Оптимизация продуктовой корзины: взаимосвязь экономических и медицинских факторов / / Экономическая политика. № 3. C. 236-257. [Korneichuk B.V. (2017). Food basket optimization: The relationship of economic and medical factors. Economic Policy. Journal for Professionals, 3, 236-257 (in Russian).]

Ляшок В.Ю., Назаров В.С., Орешкин М.С. (2016). Факторы роста размера пенсий в современной России / / Финансовый журнал. №1. С. 7-22. [Lyashok V.Yu., Nazarov V.S., Oreshkin M.S. (2016). Growth factors of the size of pensions in modern Russia. Financial Journal, 1, 7-22 (in Russian).]

Ржаницына Л.С. (2019). Стандарт экономической устойчивости семьи - новый ориентир политики доходов // Народонаселение. № 1 (23). С. 122-129. [Rzhanitsyna L.S. (2019). The standard of economic sustainability of the 
family is a new guideline for income policy. Population, 1 (23), 122-129 (in Russian).]

Соловьев А.К. (2014). Коэффициент замещения трудовой пенсии как критерий әффективности пенсионной системы // Экономическая политика. № 3. C. 61-92. [Soloviev A.K. (2014). Labor pension replacement rate as a criterion for the effectiveness of the pension system. Economic Policy. Journal for Professionals, 3, 61-92 (in Russian).]

Соловьев А.К., Герман Ю.А. (2013). Коэффициент замещения трудовой пенсии: методы исчисления и проблемы применения / / Уровенъ жизни населения регионов России. № 5. C. 30-43. [Soloviev A.K., German Yu.A. (2013). Labor pension replacement rate: Calculation methods and application problems. Living Standards of the Population in the Regions of Russia, 5, 30-43 (in Russian).]

Соловьев А.К., Донцова С.А. (2008). Проблемы применения показателя коэффициента замещения трудовой пенсии / / Уровенъ жизни населения регионов России. № 8. C. 37-50. [Soloviev A.K., Dontsova S.A. (2008). The problems of applying the indicator of the replacement rate of labor pension. Living Standards of the Population in the Regions of Russia, 8, 37-50 (in Russian).]

Draxler J., Mortensen J. (2009). Towards sustainable but still adequate pensions in the $E U$. Theory, trends and simulations, ENEPRI research report. Brussels: Centre for European Policy Studies.

European Commission (2012). The 2012 ageing report: Economic and budgetary projections for the 27 EU Member States (2010-2060). Brussels: European Commission.

European Commission (2018). Smarter, greener, more inclusive? Indicators to support the Europe 2020 strategy. Luxembourg: Publications Office of the European Union. $112 \mathrm{p}$.

Grech A.G. (2013). How best to measure pension adequacy. Centre for Analysis of Social Exclusion. CASE/172. London: London School of Economics.

Holzmann R., Hinz R. (2005). Old-age income support in the 21st century: An international perspective on pension systems and reform. Washington D.C.: The World Bank.

OECD (2011). Pensions at a Glance 2011: Retirement-income systems in OECD and G20 countries. Paris: OECD Publishing.

OECD (2016). Factbook 2015-2016: Economic, environmental and social statistics. Paris: OECD Publishing. $223 \mathrm{p}$.

OECD (2017). Pensions at a glance 2017: OECD and G20 indicators. Paris: OECD Publishing.

Social Protection Committee (2000). Adequate and sustainable pensions. Report by the Social Protection Committee on the future evolution of social protection (for the Göteborg European Council).

Поступила в редакиию 25.08.2020

Received 25.08.2020 


\title{
Y.M. Gorlin
}

Institute for Social Analysis and Forecasting, Russian Presidential Academy of National Economy and Public Administration, Moscow, Russia

\section{A.A. Salmina}

Institute for Social Analysis and Forecasting, Russian Presidential Academy of National Economy and Public Administration, Moscow, Russia

\section{V.Y. Lyashok}

Institute for Social Analysis and Forecasting, Russian Presidential Academy of National Economy and Public Administration, Moscow, Russia

\section{Empirical pension indicators: Cross-country comparisons and methodology for Russia ${ }^{15}$}

\begin{abstract}
The article proposes a system of empirical indicators for Russia, taking into account the analysis of foreign and Russian approaches to assessing the adequacy of the level of pension provision. One group of the indicators, designed for crosscountry comparisons, is based on the methodology of the European Commission. The results of calculations of the proposed indicators on Russian data are presented, which made it possible to compare the level of pensions in Russia and European Union countries. The article defines the limitations of indicators for cross-country comparisons in terms of assessing the level of pension payments within the Russian system of compulsory pension insurance. For more adequate assessment of the adequacy of payments, the second group of indicators was developed that take into account the particularities of the Russian pension system. A distinctive feature of the proposed approach to the assessment of empirical indicators is that they are focused primarily on assessing the adequacy of the actual pension payments in terms of fulfilling the functions assigned to them - protection from poverty, compensation (replacement) of wages and ensuring the balance of income. The authors propose to evaluate these indicators not only on the data of population surveys, as is most common in foreign practice, but also on the administrative data of the Pension Fund of the Russian Federation.
\end{abstract}

Keywords: pension, pension system, pension indicators, pension adequacy, replacement rate.

JEL Classification: H55, H75, J32.

DOI: $10.31737 / 2221-2264-2021-52-4-5$

${ }^{15}$ The article was written on the basis of the RANEPA state assignment research programme.

The authors express special gratitude to Elena Grishina, head of the department «Living standards and social protection» of the Institute for Social Analysis and Forecasting, RANEPA, for the valuable comments and suggestions. 